\title{
Prevalence of pre-frailty for the component of gait speed in older adults
}

\author{
Maria Helena Lenardt ${ }^{1}$ \\ Nathalia Hammerschmidt Kolb Carneiro ${ }^{2}$ \\ Susanne Elero Betiolli ${ }^{3}$ \\ Dâmarys Kohlbeck de Melo Neu Ribeiro ${ }^{3}$ \\ Patrick Alexander Wachholz ${ }^{4}$
}

Objective: to investigate pre-frailty and the factors associated with this condition, taking into account the measurements of the older adults' gait speed. Method: participants were selected by means of inclusion/exclusion criteria and a cognitive tracking test. The sample was calculated based on the estimation of populational proportion and made up of 195 older adults who were using a Primary Health-Care Center in Curitiba in the state of Paraná. Data was collected using a sociodemographic/clinical questionnaire and the gait speed test. Results: pre-frailty for gait speed has moderate prevalence (27.3\%), and is associated with the $60-69$ years age range, a low level of schooling, not feeling oneself to be alone, using anti-hypertensives, having cardiovascular disease and being overweight. Conclusion: it is considered relevant to identify those older adults with pre-frailty, as this creates the possibility for immediate intervention with the aim of stabilizing the picture. There is a significant shortage of studies on the syndrome of frailty in Brazilian older adults, principally referring to components in isolation. Given that gerontological nursing is at an early stage regarding this issue, it is understood that the identification of the prevalence must be the key point of the research on the matter.

Descriptors: Frail Elderly; Nursing; Gait.

\footnotetext{
${ }_{1}^{1}$ PhD, Retired Professor, Departamento de Enfermagem, Universidade Federal do Paraná, Curitiba, PR, Brazil.

2 Master's Student, Departamento de Enfermagem, Universidade Federal do Paraná, Curitiba, PR, Brasil. Scholarship holder at the Coordenação de Aperfeiçoamento de Pessoal de Nível Superior (CAPES).

${ }^{3}$ Doctoral Student, Departamento de Enfermagem, Universidade Federal do Paraná, Curitiba, PR, Brasil. Scholarship holder at the Coordenação de Aperfeiçoamento de Pessoal de Nível Superior (CAPES).

${ }^{4}$ Master's Student, Universidade Estadual Paulista Júlio de Mesquita Filho. Physician, Irmandade Santa Casa de Macatuba, Macatuba, SP, Brazil.
} 


\section{Introduction}

Senescence involves a wide range of physiological and psychosocial changes which accompany the natural process of aging in humans ${ }^{(1)}$. The action of personal and environmental factors over the course of an individual's life, in conjunction with the interaction caused by the person's genetic inheritance (whether this is protective or detrimental) can, as the years go by, impede the more traditional delimitation of concepts such as natural aging (senescence) and aging with frailty, which are usually separated - principally in very elderly individuals - by a tenuous line.

Although there is not a consensus regarding its definition, aging with frailty is understood as a clinical state of vulnerability to stressing factors, which results in a decline in the physiological reserves, with a subsequent reduction in the efficiency of homeostasis ${ }^{(2-3)}$. Two large prospective populational studies, the Women's Health and Aging Studies (WHAS) ${ }^{(1)}$ and the Cardiovascular Health Study $(\mathrm{CHS})^{(4)}$, operationalized and validated the phenotypic criteria for the syndrome of frailty and prefrailty most used at the present time, through evaluating the following components: unintentional weight loss, reduction in the strength of hand grip, reduction in physical activity, self-reported fatigue and reduction in gait speed.

According to these criteria, an older adult is considered frail if he or she meets three or more of the five characteristics of the syndrome of frailty; the prefrail phenotype encompasses those individuals who meet only one or two of the above-mentioned components; the older adults with negative or normal responses to the five elements are considered non-frail(2).

Gait speed has been studied as a potential predictor for adverse events, and its correlation with the cycle of frailty has been suggested in preliminary investigations ${ }^{(5-7)}$. This study's object was to investigate pre-frailty and the factors associated with this condition, taking gait speed into account, in older service users of a Primary Health-Care Center in the South of Brazil.

\section{Methods}

This is a quantitative, cross-sectional study carried out in a Primary Health-Care Center (UBS) in the city of Curitiba, Paraná. The target population was made up of older adults aged 60 or over who were waiting for a consultation in the UBS, in the period September 2010 - March 2011.
The size of the sample was determined based on the estimation of the populational proportion. A degree of confidence of $95 \%(\alpha=0.05)$, a variance of 0.12 and a sampling error fixed at five percentage points were taken into account. $10 \%$ was added to the size of the sample because of the possibility of losses or refusals, which resulted in a sampling plan of 203 older adults.

The following inclusion criteria were adopted for selecting the older adults: (a) to be aged sixty or over; (b) to have a score above the cut-off point (according to level of schooling) on the administration of the MiniMental State Examination (MMSE) cognitive test ${ }^{(8)}$ : a minimum of 13 points for illiterates, 18 points for those with medium to low schooling, and 26 points for those with a high level of schooling(9) and (c) to be able to walk around, with or without support.

Older adults were excluded if they had previous diagnoses of severe physical or mental illnesses or handicaps, which could hinder participation in the stages of interview and evaluation of the phenotypes of frailty and of walking, or which raised an unacceptable risk of falls while carrying out the latter.

The sample was recruited by convenience and the individuals were invited to participate in the study in the order of their arrival at the reception of the UBS. The objective of the research was explained and those who were willing to participate signed the Terms of Free and Informed Consent (TCLE). Following this, in a reserved area termed the Health Space, the Mini-Mental State Examination (MMSE) ${ }^{(8)}$ was administered, for tracking of changes in cognitive function (cognitive screening) in the older adults.

Following this, the socio-demographic questionnaire and the gait speed test were administered. The sociodemographic variables investigated were: age, marital state, with whom the older adult lived, level of schooling and family income. The clinical variables included: health problems, number of hospitalizations, history of falls, feelings of solitude, urinary function, use of cigarettes and alcohol, use of assistive technology (walking stick, walking frame, crutches, corrective lenses) use of medication and Body Mass Index (BMI).

One literature review ${ }^{(5)}$ discusses 9 cohort studies, which associated gait speed tests over a distance of six meters. In a similar way, a separate international literature review study ${ }^{(10)}$, which assessed the applicability of gait speed tests, indicates that the marking of 6 meters suggested by the authors ${ }^{(5,11)}$ has been widely used for elderly patients and that usually these are timed over 4 to 6 meters of walking, according to the aim of the researchers' study. 
For this reason, in order to evaluate the gait speed, the older adults were advised to walk six meters, in their usual way, on a flat surface, signposted with four marks: start, one meter, five meters, and end. So as to reduce the effects of acceleration and deceleration, the test was started one meter before the second reference, and the walk was interrupted one meter after the third mark $^{(11)}$. The digital stopwatch measured the time taken in seconds for covering the four meters.

Gait speed was calculated in meters per second $(\mathrm{m} / \mathrm{s})$, in line with an international study on frailty in older adults ${ }^{(4)}$, so as to realize comparisons. In the study in question ${ }^{(4)}$, values in the lower quintile (the value in which $20 \%$ of the sorted sample is found) were considered as frailty markers. In the present investigation, however, because of the computer program used, the lower quartile (a value in which $25 \%$ of the sorted sample is found) was used as the frailty marker.

The data was organized and stored in the Excel ${ }^{\circledR}$ 2007 software, in which the subjects were separated according to their level of frailty (pre-frail and non-frail older adults, according to the gait speed marker). The EpiInfo software, version 6.04, was used for analyzing the results, and descriptive statistics was applied, through the distribution of the absolute and percentual frequencies, the mean and standard deviation, and non-parametric tests (Chi-squared and Fisher) for the association of variables. The results were considered statistically significant when $p<0.05$, that is, with a level of significance of $5 \%$.

The study was approved by the Health Sciences Department Ethics Committee for Research on Human Beings, being approved under record CEP/SD: 913.038.10.04 CAAE: 0023.0.091.000-10. The ethical precepts of the voluntary and consensual participation of each subject were respected.

\section{Results}

After applying the inclusion and exclusion criteria proposed for the study, the final sample was made up of 195 older adults. Of the total of older adults, $27.3 \%$ had reduced gait speed, and were classified as in a pre-frail condition for this component.

Regarding the socio-demographic profile of the older adults with reduced gait speed (27.3\%), 18\% are female and $9.3 \%$ are male. There was a prevalence of the age range from 60 to 69 years $(10.8 \%$; Table 1$)$, with the minimum age being 60 years and the maximum age being 93 years ( $m e a n=72.90 ; \pm 7.9$ ).

It can be seen from Table 1 that $11.3 \%$ of the older adults who were pre-frail for this component stated themselves to be widowed and the majority (18\%) live with more than one family member. Regarding level of schooling, $15.4 \%$ of the older adults had not finished basic education, and $13 \%$ considered their financial situation to be average.

Table1 - Socio-demographic profile of the older adult with pre-frailty for gait speed. Curitiba, PR, Brazil, 2011

\begin{tabular}{|c|c|c|c|c|}
\hline \multirow{2}{*}{ Variable/Classification } & Pre-frail for $\mathbf{G S}^{*}$ & Non-frail for $\mathbf{G S}^{*}$ & Total & \multirow{2}{*}{ P value $^{\dagger}$} \\
\hline & $n(\%)$ & n (\%) & n (\%) & \\
\hline \multicolumn{5}{|l|}{ Sex } \\
\hline Male & $18(9.3)$ & $65(33.3)$ & $83(42.6)$ & \multirow{2}{*}{0.137} \\
\hline Female & $35(18.0)$ & $77(39.4)$ & $112(57.4)$ & \\
\hline \multicolumn{5}{|l|}{ Age } \\
\hline 60 to 69 years & $21(10.8)$ & $86(44.1)$ & $107(54.9)$ & \multirow{3}{*}{$<0.001^{\dagger}$} \\
\hline 70 to 79 years & $19(9.8)$ & $48(24.5)$ & $67(34.3)$ & \\
\hline 80 years or over & $13(6.7)$ & $08(4.1)$ & $21(10.8)$ & \\
\hline \multicolumn{5}{|l|}{ Marital status } \\
\hline Widow(er) & $22(11.3)$ & 37 (18.9) & $59(30.2)$ & \multirow{4}{*}{0.084} \\
\hline Married & $19(9.8)$ & $79(40.5)$ & $98(50.3)$ & \\
\hline Divorced & $06(3.1)$ & $15(7.7)$ & $21(10.8)$ & \\
\hline Single & $06(3.1)$ & $11(5.6)$ & $17(8.7)$ & \\
\hline \multicolumn{5}{|l|}{ Who lives with } \\
\hline Family member & $35(18.0)$ & $89(45.6)$ & $124(63.6)$ & \multirow{3}{*}{0.855} \\
\hline Spouse & $10(5.2)$ & $32(16.3)$ & $42(21.5)$ & \\
\hline Alone & $08(41)$ & $21(10.8)$ & $29(14.9)$ & \\
\hline
\end{tabular}


Table 1 - (continuation)

\begin{tabular}{|c|c|c|c|c|}
\hline \multirow{2}{*}{ Variable/Classification } & Pre-frail for GS* & Non-frail for $\mathbf{G S}^{*}$ & Total & \multirow{2}{*}{$\mathrm{P}$ value ${ }^{\dagger}$} \\
\hline & $\mathrm{n}(\%)$ & $\mathrm{n}(\%)$ & $n(\%)$ & \\
\hline \multicolumn{5}{|l|}{ Schooling } \\
\hline Junior high incomplete & $30(15.4)$ & $91(46.5)$ & $121(61.9)$ & \multirow{6}{*}{$0.015^{\dagger}$} \\
\hline Illiterate & $14(7.2)$ & $16(8.2)$ & $30(15.4)$ & \\
\hline High school complete & $06(3.1)$ & $15(7.7)$ & $21(10.8)$ & \\
\hline High school incomplete & $03(1.6)$ & $03(1.6)$ & $06(3.2)$ & \\
\hline Junior high complete & $0(0)$ & $15(7.7)$ & $15(7.7)$ & \\
\hline Higher education & $0(0)$ & $02(1.0)$ & $02(1.0)$ & \\
\hline \multicolumn{5}{|l|}{ Financial Situation } \\
\hline Average & $25(13.0)$ & $99(50.6)$ & $124(63.6)$ & \multirow{4}{*}{0.126} \\
\hline Satisfactory & $17(87)$ & $08(4.1)$ & $25(12.8)$ & \\
\hline Insatisfactory & $11(56)$ & $35(18.0)$ & $46(23.6)$ & \\
\hline Total & $53(27.3)$ & $142(72.7)$ & 195(100) & \\
\hline
\end{tabular}

NB: Result expressed by frequency (percentual).

*Chi-Squared test, $\mathrm{p}<0.05$

tGait Speed

The majority of the older adults with reduced gait speed have health problems (26.2\%). The illnesses reported were classified according to their distinctive characteristics and grouped in the following way: cardiovascular, musculo-skeletal, of the digestive system, metabolic, respiratory, auditory, dyslipidemias, visual, urological and others. Cardiovascular illnesses predominated $(32.1 \%)$ and the number of illnesses varied from zero to nine (mean 2.76; \pm 1.7 ; Table 2).

It was possible to note a significant quantity of older adults who stated that they had not received inpatient treatment or suffered an episode of falling in the previous twelve months $(21.1 \%$ and $18.5 \%$, respectively), did not feel lonely $(15.3 \%)$, did not suffer from urinary incontinence $(17.4 \%)$, did not smoke (24.7\%) and did not drink alcohol (24.1\%). Further, regarding the use of assistive technology, the majority reported that they do not use walking sticks $(25.1 \%)$, walkers $(27.1 \%)$ or crutches $(26.6 \%)$. The use of glasses was mentioned by $23.5 \%$ of the older adults (Table 2 ).

Table 2 - Clinical profile of the older adult with pre-frailty for gait speed. Curitiba, PR, Brazil, 2011

\begin{tabular}{|c|c|c|c|c|}
\hline \multirow{2}{*}{ Variable /Classification } & Pre-Frail for $\mathbf{G S}^{*}$ & Non-Frail for GS* & Total & \multirow{2}{*}{ P value $^{\dagger}$} \\
\hline & n (\%) & n (\%) & n (\%) & \\
\hline \multicolumn{5}{|l|}{ Health problems } \\
\hline Yes & $51(26.2)$ & $125(64.1)$ & $176(90.3)$ & \multirow{2}{*}{0.080} \\
\hline No & $02(1.0)$ & $17(8.7)$ & $19(9.7)$ & \\
\hline \multicolumn{5}{|l|}{ Hospitalizations } \\
\hline Yes & $12(6.1)$ & $24(12.3)$ & $36(18.4)$ & \multirow{2}{*}{0.358} \\
\hline No & $41(21.1)$ & $118(60.5)$ & $159(81.6)$ & \\
\hline \multicolumn{5}{|l|}{ Falls } \\
\hline Yes & $17(8.7)$ & $38(19.4)$ & $55(28.3)$ & \multirow{2}{*}{0.463} \\
\hline No & $36(18.5)$ & $104(53.4)$ & $140(71.7)$ & \\
\hline \multicolumn{5}{|l|}{ Lonely } \\
\hline Yes & $23(11.8)$ & $35(18.0)$ & $58(29.8)$ & \multirow{2}{*}{$0.010^{*}$} \\
\hline No & $30(15.3)$ & $107(54.9)$ & $137(70.2)$ & \\
\hline \multicolumn{5}{|l|}{ Urinary Incontinence } \\
\hline Yes & $19(9.8)$ & $40(20.5)$ & $59(30.3)$ & \multirow{2}{*}{0.298} \\
\hline No & $34(17.4)$ & $102(52.3)$ & $136(69.7)$ & \\
\hline
\end{tabular}


Table 2 - (continuation)

\begin{tabular}{|c|c|c|c|c|}
\hline \multirow{2}{*}{ Variable /Classification } & Pre-Frail for $\mathbf{G S}^{*}$ & Non-Frail for $\mathbf{G S}^{*}$ & Total & \multirow{2}{*}{ P value } \\
\hline & n (\%) & n (\%) & n (\%) & \\
\hline \multicolumn{5}{|l|}{ Smoker } \\
\hline Yes & $05(2.5)$ & $13(6.7)$ & $15(9.2)$ & \multirow{2}{*}{0.952} \\
\hline No & $48(24.7)$ & $129(66.1)$ & $177(90.8)$ & \\
\hline \multicolumn{5}{|l|}{ Alcohol consumer } \\
\hline Yes & $06(3.1)$ & $19(9.7)$ & $25(12.8)$ & \multirow{2}{*}{0.701} \\
\hline No & $47(24.1)$ & $123(63.1)$ & $170(87.2)$ & \\
\hline \multicolumn{5}{|l|}{ Walking Stick } \\
\hline Yes & $04(2.0)$ & $04(2.0)$ & $08(4.0)$ & \multirow{2}{*}{0.138} \\
\hline No & $49(25.1)$ & 138(70.9) & $187(96.0)$ & \\
\hline \multicolumn{5}{|l|}{ Walker } \\
\hline Yes & $0(0)$ & $01(0.5)$ & $01(0.5)$ & \multirow{2}{*}{0.540} \\
\hline No & $53(27.1)$ & $141(72.4)$ & $191(99.5)$ & \\
\hline \multicolumn{5}{|l|}{ Crutches } \\
\hline Yes & $01(0.5)$ & $01(0.5)$ & $02(1.0)$ & \multirow{2}{*}{0.465} \\
\hline No & $52(26.6)$ & $141(72.4)$ & $193(99.0)$ & \\
\hline \multicolumn{5}{|l|}{ Ocular Prosthesis } \\
\hline Yes & $46(23.5)$ & $135(69.3)$ & $181(92.8)$ & \multirow{2}{*}{0.341} \\
\hline No & $07(3.6)$ & $07(3.6)$ & $14(7.2)$ & \\
\hline \multicolumn{5}{|l|}{ Medications } \\
\hline Yes & $52(26.6)$ & $137(70.3)$ & $189(96.9)$ & \multirow{2}{*}{0.182} \\
\hline No & $01(0.5)$ & $05(2.6)$ & $06(3.1)$ & \\
\hline \multicolumn{5}{|l|}{ Body Mass Index (BMI) } \\
\hline Low Weight & $01(0.5)$ & $0(0)$ & $01(0.5)$ & \multirow{4}{*}{$0.005^{\dagger}$} \\
\hline Eutrophy & $22(11.3)$ & $41(21.0)$ & $63(32.3)$ & \\
\hline Overweight & $30(15.3)$ & $101(51.9)$ & $131(67.2)$ & \\
\hline Total & $53(27.3)$ & $142(72.7)$ & $195(100)$ & \\
\hline
\end{tabular}

NB: Results expressed by frequency (percentual)

*Chi-Squared Test, $\mathrm{p}<0.05$

+Gait Speed

The quantity and the class of the medications used varied among the older adults in the sample. It may be observed that $9.8 \%$ use five or more medications, with the maximum number of medications used being 16 . The main classes of drugs used by the older adults with reduced gait speed were: antihypertensives (24.1\%), oral hypoglycemics (11.3\%) and anti-inflammatories $(9.8 \%)$. It is noteworthy that $15.3 \%$ had a BMI compatible with being overweight.

Among the older adults, the slowest gait speed was $0.29 \mathrm{~m} / \mathrm{s}$, and the fastest was $0.71 \mathrm{~m} / \mathrm{s}$, with a mean of $0.50 \mathrm{~m} / \mathrm{s}$. Among the males, the slowest speed was 0.24 $\mathrm{m} / \mathrm{s}$, the fastest was $0.71 \mathrm{~m} / \mathrm{s}$, and the mean was 0.47 $\mathrm{m} / \mathrm{s}$. The value of the speed corresponding to the lower quartile identified in the sample was equal to $0.71 \mathrm{~m} / \mathrm{s}$.

There was a significant association between prefrailty for gait speed and the socio-demographic variables of age $(p<0.001)$ and schooling $(p=0.015)$. The clinical variables which were significantly associated with reduced gait speed were: presence of cardiovascular diseases $(p=0.003)$; use of antihypertensives $(p=0.005)$; not feeling lonely $(p=0.010)$; and BMI compatible with being overweight $(p=0.005)$.

\section{Discussion}

The distribution of the 53 older adults with frailty for gait speed shows $18 \%$ female and $9.3 \%$ male, which is consistent with studies in which female longevity was identified, a phenomenon known as the feminization of aging(12) Although older adults nowadays have the advantage of longevity, they were also more frequently the victims of discrimination in access to education, salary, food, meaningful work and political power. These cumulative disadvantages mean that older women tend to be poorer and present greater disabilities at more advanced ages ${ }^{(13)}$. 
The men obtained a lower mean gait speed $(0.47 \mathrm{~m} / \mathrm{s})$ than the women $(0.50 \mathrm{~m} / \mathrm{s})$. These results diverge from those from research(14) which assessed the results of eight cohort studies undertaken in the United Kingdom, which covered approximately 40,000 individuals aged between 50 and 90 years. The study(14) showed that the women's gait speed results were lower than the men's, although this difference was attenuated after adjusting for body size. According to the study(14), gait speed tends to reduce gradually with aging, at a more accelerated rate between 65 and 85 years, and with a decline which is more accentuated among women compared to among the men.

However, in like manner to the present study, a study undertaken in Peru(15) with 246 older adults, which aimed to determine the factors associated with reduction in gait speed, also did not indicate a significant relationship between this variable and the sex of the participants. Thus, it is suggested that further investigations focussing on this should be undertaken, so that a better relationship between gait speed and gender in older adults may be established.

In the relation between older adults' age and gait speed, a significant difference was observed in the group aged from 60 to 69 years $(p<0.001)$. This age range had a mean speed of $0.67 \mathrm{~m} / \mathrm{s}$, whereas the older adults aged between 70 and 79 had a mean speed of $0.58 \mathrm{~m} / \mathrm{s}$ and those aged 80 or over had a mean speed of $0.50 \mathrm{~m} / \mathrm{s}$. These results match those found in the literature(14-15), demonstrating that older adults aged 80 or over present reduced gait speed more frequently. This may be explained, in part, by the aging process, in which physiological changes in neuro-musculoskeletal function occur ${ }^{(16)}$.

There was a significant relationship between gait speed and low schooling $(p=0.015)$. Of the 53 older adults, $22.6 \%$ did not finish Junior High School. A study ${ }^{(17)}$ carried out with 235 older adults ascertained that the probability of those with the lowest level of schooling manifesting moderate to severe functional dependence was five times greater than those with a high level of schooling. Those individuals with the lowest level of schooling tend more frequently to adopt habits which are prejudicial to health, whether this is through difficulty in accessing information or because of living conditions which lead to the incorporation of behaviors considered unhealthy ${ }^{(18)}$.

Health problems were reported by $90.3 \%$ of the participants in the present investigation. Of these, $26.2 \%$ had altered gait speed. In spite of the high prevalence of illnesses referred to by the older adults, attention is drawn to the scarcity of data in the literature relating the presence of morbidities and prefrailty to gait speed. However, regarding the scale of the frequency of the illnesses, this research's result is similar to the findings of an epidemiological study carried out in the municipality of São Paulo(19), in which 2,143 older adults participated. According to the results of that investigation, high blood pressure was the most prevalent illness, being observed in $53.3 \%$ of the older adults; followed by arthritis/rheumatism/arthrosis in $31.7 \%$; cardiac problems in $18.2 \%$; and diabetes mellitus in $17.8 \%$ of the participants ${ }^{(19)}$.

The research ${ }^{(19)}$ cited above points out, further, that the main signs and symptoms mentioned by the older adults who had cardiovascular illnesses were: chest pain; swelling in the feet and ankles; persistent vertigo/dizziness; and severe fatigue or tiredness. It is believed that these factors are important when considering change in gait speed, which constitutes a possible explanation for the significant result between these two variables.

Of the older adults who needed drug therapy $(96.9 \%), 26.6 \%$ had a reduced gait speed. Of these, $9.8 \%$ used more than five medications, which constitutes polypharmacy (use of five or more medications), an effect observed in various studies already undertaken with the elderly population. According to research(20) undertaken with 1,598 older adults resident in the metropolitan region of Belo Horizonte in the state of Minas Gerais, there was a moderate percentage of polypharmacy (14.3\%) among the subjects interviewed. Results such as these show the importance of attitudes to be taken for the quantities of medications taken to be reduced where possible.

The majority of the participants use antihypertensives (69.2\%). Among these, $24.1 \%$ are pre-frail for the component studied. A similar result was indicated by a study ${ }^{(19)}$ in which $80.6 \%$ of the older adults used this type of medication. The association between reduction in gait speed and use of antihypertensives was shown to be statistically significant, with a value of $p=0.005$, which suggests that some of the symptoms resulting from high blood pressure - such as dizziness and tiredness - may entail changes in older adults' gait speed.

One may observe in the literature works which relate the reduction in gait speed with greater incidence of falls in older adults(18-21). In the present study, however, there was no statistically significant 
association between these variables. A study ${ }^{(22)}$ which assessed walking in older adults aged 82 or over concluded that changes in walking, as adaptations for gaining stability, are adaptations made by older people in response to fear of falling. Hence, it is to be expected that reducing speed should contribute to a reduction in the incidence of falls rather than to an increase in the same. The investigation ${ }^{(22)}$ supports the hypothesis that the predictive factor for the tendency to fall among older adults is the variability of the temporal and spatial data of the act of walking during the pacing rather than the reduction in the speed resulting from the aging process.

The self-reporting by older adults of "not feeling lonely" was associated significantly with reduction in gait speed $(p=0.010)$. Data was not found in the scientific literature permitting the discussion of the relationship between these variables. This finding may be explained by the subjectivity present in feeling oneself to be lonely or not, which could not be investigated here due to the present study's quantitative approach. A qualitative investigation could possibly contribute to an understanding of this relationship.

The high rate of overweightness ( $n=30 ; 15.3 \%)$ in the present study stands out, this being shown to be statistically significant in reducing gait speed $(p=0.005)$. One investigation(23) which assessed BMI in 699 older adults in the community also indicated a higher rate (50\%) of overweightness in the individuals evaluated. Among the innumerable consequences of being overweight, one may cite the wear on the joints as a factor influencing the older adult's walking. One should also stress the scarcity in the literature of studies which directly relate BMI with gait speed, which indicates evidence for further studies.

The instrument of evaluation of gait speed was shown to be useful as an indicator for pre-frailty in older adults, given the prevalence of its relationship with this condition. In addition to this, it is an easy test to apply and one which does not require great resources to be carried out, being able to be realize widely in health institutions. In isolation, it was shown to be capable of identifying slowing-down of gait speed among the older adults investigated, which is considered a possible sign of deficit in functional capacity and presence of illnesses related to walking. One cannot, however, infer that this type of evaluation indicates changes in the older adult's general state of health. For that, it would be necessary to include variables which evidence the older adults' state of health in association with the gait speed.

\section{Conclusion}

Moderate prevalence of pre-frailty for gait speed is inferred in the older adults evaluated (27.3\%). Thus, primary care health professionals who work directly with this population should consider identifying the older adults who are in this pre-frailty condition and investigate how it relates with the socio-demographic and clinical variables - as there is the possibility of immediate intervention with the aim of stabilizing the picture.

The factors associated with the condition of prefrailty indicated by the reduction in gait speed were: age range between 60 and 69, low schooling, not feeling oneself to be lonely, having cardiovascular disease, using antihypertensive, and being overweight. Identifying these variables makes it possible for health professionals working in geriatrics and gerontology to elaborate an action plan which aims to minimize the harm caused by this condition and, consequently, the slowing of gait.

The study's quantitative approach did not allow the understanding of specific relationships with subjective variables. To that end, the undertaking of further studies with a qualitative focus is suggested, as these would permit better interpretations of, and extraction of meaning from, the statistical data.

The Brazilian literature is significantly short of studies which assess the condition of pre-frailty in older adults, regarding the reduction in gait speed. In the same way, there is a shortage of investigations relating this component with the socio-demographic and clinical variables of individuals who live in the community. The publication of works in this area would help in a better understanding of the variables associated with the reduction in gait speed. This contribution represents an important advance in the construction of knowledge concerning the syndrome of frailty in older adults.

\section{References}

1. Lowry KA, Vallejo AN, Studenski SA. Successful Aging as a Continuum of Functional Independence: Lessons from Physical Disability Models of Aging. Aging and Disease. 2012;3(1):5-15.

2. Fried L, Ferrucci L, Darer J, Williamson JD, Anderson G. Untangling the concepts of disability, frailty and comorbidity: implications for improved targeting and care. J. Gerontol A Biol Sci Med Sci. 2004;59(3):255-63. 3. Xue QL. The frailty syndrome: definition and natural history. Clin Geriatr Med. 2011;27(1):1-15. 
4. Fried L, Tangen CM, Walston J, Newman AB, Hirsch

C, Gottdiener J, et al. Frailty in older adults: Evidence for a phenotype. J. Gerontol A Biol Sci Med Sci. 2001; 56A(3): 146-56.

5. Studenski S, Perera S, Patel K, Rosano C, Faulkner K, Inzitari $M$, et al. Gait speed and survival in older adults. Jama. 2011;(305):50-8.

6. Varela Pinedo L, Ortiz Saavedra PJ, Chávez Jimeno $\mathrm{H}$. Gait speed as an indicator of fragility in communitydwelling elders in Lima, Peru. Rev Esp Geriatr Gerontol. 2010;45(1):22-5.

7. Afilalo J. Frailty in Patients with Cardiovascular Disease: Why, When, and How to Measure. Curr Cardiovasc Risk Rep. 2011;5(5):467-72.

8. Folstein MF, Folstein SE, McHugh PR. "Mini-mental state": a practical method for grading the cognitive state of patients for the clinician. J.Psychiatr Res. 1975;12(3):189-98.

9. Bertolucci PH, Brucki SM, Campacci SR, Juliano Y. The Mini-Mental State Examination in a general population: impact of educational status. Arq. Neuro-Psiquiatr. $1994 ; 52(1): 1-7$.

10. Graham JE, Ostir GV, Kuo Y, Fisher SR, Ottenbacher JK. Relationship Between Test Methodology and Mean Velocity in Timed Walk Tests: A Review.Arch Phys Med Rehabil. 2008;89(5):865-72.

11. Geraldes AAR, Oliveira ARM, Albuquerque RB, Carvalho JM, Farinatti PTV. A força de preensão manual é boa preditora do desempenho funcional de idosos frágeis: um estudo correlacional múltiplo. Rev Bras Med Esporte. 2008;14(1):12-6.

12. Camarano AA. Mulher idosa: suporte familiar ou agente de mudança? Estud. av. 2003;17(49):35-63.

13. Feliciano $A B$, Moraes SA, Freitas ICM. O perfil do idoso de baixa renda no Município de São Carlos, São Paulo, Brasil: um estudo epidemiológico. Cad. Saúde Pública. 2004;20(6):1575-85.

14. Cooper R, Hardy R, Sayer AA, Ben-Shlomo, Birnie $\mathrm{K}$, Cooper $\mathrm{C}$, et al. Age and Gender Differences in Physical Capability Levels from Mid-Life Onwards: The Harmonisation and Meta-Analysis of Data from Eight UK Cohort Studies. PLOS ONE [internet]. 2011 [acesso em: 06 nov 2012];11(6):e27899. Disponível em: http://www.plosone.org/article/ info\%3Adoi\%2F10.1371\%2Fjournal. pone.0027899

15. Fernando VPL, José OSP, Alejandro $\mathrm{CJH}$. Velocidad de la marcha en adultos mayores de la comunidad en Lima, Perú. Rev Med Hered. 2009;20(3):133-8.
16. Schenatto P, Milano D, Berlezi EM, Bonamigo ECB. Relação entre aptidão muscular e amplitude articular, por faixa etária, na marcha do idoso. Rev. Bras. Geriatr. Gerontol. 2009;12(3):377-89.

17. Rosa TEC. Fatores determinantes da capacidade funcional de idosos. Rev. Saúde Pública. 2003;37(1):40-8. 18. Maciel ACC, Araújo LM. Fatores associados às alterações na velocidade de marcha e força de preensão manual em idosos institucionalizados. Rev. Bras. Geriatr. Gerontol. 2010;13(2):179-89.

19. Lebrão $M L$, Laurenti R. Sáude, bem-estar e envelhecimento: o estudo SABE no município de São Paulo. Rev Bras Epidemiol. 2005;8(2):127-41.

20. Loyola Filho AI, Uchoa E, Lima-Costa MF. Estudo epidemiológico de base populacional sobre o uso de medicamentos entre idosos na Região Metropolitana de Belo Horizonte, Minas Gerais, Brasil. Cad. Saúde Pública. 2006;22(12):2657-67.

21. Figliolino JAM. Análise da influência do exercício físico em idosos com relação a equilíbrio, marcha e atividade de vida diária. Rev Bras de Geriatria e Gerontologia. 2009;12(2):227-38.

22. Maki BE. Gait changes in older adults: predictors of falls or indicators of fear. J Am Geriatr Soc. 1997;45(3):313-20.

23. Santos DM, Sichieri R. Índice de massa corporal e indicadores antropométricos de adiposidade em idosos. Rev. Saúde Pública. 2005;39(2):163-8. 